\title{
Mandatory Faculty Development Works
}

\section{Mona B. Kreaden}

New York University

This chapter tells the story of a successful, ongoing, mandatory faculty development program. It explains the bistorical reasons why a business school in a large, urban Research I institution felt the need to make their program mandatory, examines how it was developed, and the university faculty development program's role in the process. The author makes the case that mandatory programs can be successful in faculty development when they are administered by an outside credible entity, are faculty driven, and guarantee confidentiality.

\section{INTRODUCTION}

$T^{t}$ is the conventional wisdom of faculty development practitioners that requiring faculty to participate in teaching improvement efforts would be unsuccessful because of resentment and resistance on the part of those who are being forced to participate (Morrison, 1997; Sorcinelli, 1997). Faculty members guard their autonomy and would treat any mandatory program as a threat to their academic freedom and integrity.

Yet, the Stern School of Business at New York University (NYU) has been successful in implementing the Stern Teaching Effectiveness Program (STEP), a mandatory process that requires all faculty members to participate in teaching improvement efforts. Faculty unanimously accepted its guidelines in 1996, and STEP is in the middle of its third twoyear cycle (January 2001).

The purpose of this chapter is to highlight how mandatory programs can be successful in faculty development when they are administered by an outside credible source, are faculty driven, and guarantee confidentiality. 


\section{The Stern School of Business Faculty Development Program}

Since the early 1990s, business schools increasingly competed for stature, and students' opinions of the teaching quality became increasingly important. In order to maintain the stature and standards of the Stern School of Business, the school's dean placed more emphasis on teaching quality for tenure, promotion, and merit decisions. For instance, in tenure decisions, while outstanding research generally remains as a top priority, highly effective teaching became an important consideration. This increased attention to teaching quality created the challenge of how to provide adequate support for faculty to meet the new standards.

In fall 1995, Stern's faculty council formed the Stern School Teaching Effectiveness Committee (comprised of respected Stern faculty), and charged them with the task of establishing a program that would improve teaching throughout the school. The committee met often and worked diligently to develop a proposal that was presented at the spring semester all-faculty meeting.

The EQUAL Commission (an NYU initiative to Enhance the Quality of Undergraduate Academic Life) was created in 1993 as a faculty development program whose mission focused on improving teaching effectiveness throughout New York University. The director of EQUAL was known to several committee members and was invited to attend one of the meetings to discuss various efforts EQUAL was employing to improve teaching at NYU.

She discussed the efficacy of private one-to-one consultations (Piccinin, 1999) and close observations placing an emphasis on formative evaluation (Wilkerson, 1988), a form of feedback meant to help the instructor improve teaching separate and apart from summative evaluation for promotion and tenure purposes. She also stressed the importance of confidentiality in order to build trust between the faculty member and consultant.

The director offered a variety of observation processes: Small Group Instructional Diagnosis (S.G.I.D.) (Diamond, 1988) (see Appendix 8.1) as a way of engaging the students in the formative process; classroom observation while the instructor is videotaped; and a classroom observation without video. Each of these involves a pre-observation meeting between faculty member and consultant, along with follow up discussions about the observation. Subsequent visits are arranged as requested. 
EQUAL's director stressed the importance of these processes being voluntary. In order to get the best results she emphasized the necessity of faculty having a wide choice of observation methods in order to serve different teaching styles, class size and type, and instructor comfort level during the process.

The committee expressed concern that a voluntary program would not attract those needing teaching support the most and making it remedial would disadvantage faculty who were singled out. They believed that requiring every faculty member to participate in the program would be more effective. The committee did, however, take the EQUAL director's other suggestion about giving each faculty member the choice of observation offerings. Thus, the Stern Teaching Effectiveness Program (STEP) was drafted (Stern School of Business, 1996).

In addition, Stern's Teaching Committee members realized that instituting a mandatory program for faculty, without prior consent, would not engender program success. At a school-wide faculty meeting, STEP was presented and after discussion, voted upon. Despite the unorthodoxy of launching a mandatory teaching program, the faculty-at-large agreed to pilot test STEP for two years in order to gauge its effectiveness. Because the pilot was approved by the faculty-at-large, it stood a good chance of succeeding (Stern School of Business, 1996) (see Appendix 8.1 for the approved program).

\section{Implementation}

Once the pilot testing of STEP was approved, the vice dean of faculty was required to implement it and make sure it succeeded. He met with EQUAL's director in order to find out if EQUAL would be able to support three of the four evaluative procedures in STEP. (In addition to the processes the director had suggested above, Stern faculty opted for peer observation as well, where faculty members exchange observation visits.) The director agreed to provide support for STEP, if Stern would provide the resources to hire the number of consultants required to serve approximately 200 full-time faculty members.

\section{Logistics}

To avoid the possibility of 200 people requesting consultations in one semester, Stern's vice dean and EQUAL's director devised a schedule to ensure that consultations would be spread out over the full two-year pilot program, approximately 50 per semester (Table 8.1). 
An initial cohort of seven part-time consultants was recruited and trained from existing full- and part-time faculty at NYU and other institutions in the area. This number has grown to 12 part-time plus one fulltime faculty development consultant as demand for consultations grew. Consultants are paid on a per-consultation basis, rather than hourly.

Over the length of the pilot, both Stern's vice dean and EQUAL's director kept close watch on the flow of consultations, and carried on an active email dialogue with each other on its progress. At all times, consultations and reports were (and continue to be) confidential.

TABLE 8.1

Breakdown of Consultations Performed by Semester and Type

\begin{tabular}{lcccc}
\hline & $\begin{array}{c}\text { Fall } \\
\mathbf{1 9 9 6}\end{array}$ & $\begin{array}{c}\text { Spring } \\
\mathbf{1 9 9 7}\end{array}$ & $\begin{array}{c}\text { Fall } \\
1997\end{array}$ & $\begin{array}{c}\text { Spring } \\
\mathbf{1 9 9 8}\end{array}$ \\
\hline Observations & 12 & 3 & 8 & 13 \\
\hline Videos & 5 & 21 & 24 & 15 \\
\hline S.G.I.D.s & 10 & 6 & 13 & 7 \\
\hline Peer Reviews & 14 & 23 & 5 & 16 \\
\hline Totals & 41 & 53 & 50 & 51 \\
\hline
\end{tabular}

\section{Consulting Requirements}

Taking into consideration the culture of the business school, EQUAL's director knew that it was important to have consultants who were effective lecturers and teachers of large classes, as well as good discussion leaders. She also understood the importance that Stern faculty placed on content coverage and made sure to recruit consultants from Stern's Management Communication Department to serve those who felt that the understanding of content was important to the consultant's ability to give good feedback. After the first two years, there were very few faculty requests for consultants with content expertise.

\section{Consultant Recruitment}

The recruitment of consultants was and continues to be based on the following criteria.

- At least three years' experience teaching in a college classroom 
- Highly seasoned consultants who would work with more senior faculty

- Excellent reputations as teachers

- Respected as serious academics who are invested in their teaching and experienced in different pedagogical techniques, in addition to the straight lecture method

- A teaching philosophy that is student-centered

\section{Consultant Training}

Every consultant hired is observed teaching or comes highly recommended by other faculty who understand what EQUAL is looking for. As part of the consultants' orientation, they each meet individually with the director for about one hour and a half to discuss the requirements of the consulting process. They also are encouraged to contact the director with any questions or problems they encountered throughout the process.

EQUAL's director is aware that despite unanimous approval for the STEP pilot, Stern faculty may be reluctant and possibly resentful to participate in a required program. And she understands that the consultants have to be trained in order to achieve satisfactory results. In her meetings with the consultants, she stresses that every professor who requests a consultation from EQUAL must walk away from the experience with three results.

1) A feeling that they had a positive experience in the consultationthat the process "wasn't so bad"

2) A solid teaching suggestion that they can exercise without too much difficulty in the next class meeting

3) A discussion with the consultant that focuses on the faculty member's approach toward teaching

\section{Assigning Consultants}

It was important to know if faculty attitudes toward participation are resistant to participate, eager, or acquiescent because it is required. In general, faculty express the attitude that if they are going to have do it, they "may as well get something out of it." With an eye toward making the instructor feel as relaxed and open as possible, seniority, gender, attitude, and class size are taken into consideration when assigning consultants. 
Because of the large numbers of faculty involved in STEP, individual interviews with applicants are not possible. Therefore, an application form was designed describing the options faculty members can choose, and to gather enough information to assign appropriate consultants. This application also gives the assigned consultant information to open a discussion when meeting the instructor prior to the observation (see Appendix 8.2 for a sample form).

Metbodology. Consultants are trained to always be positive and to approach the process in a collaborative way-as a colleague who has been invited to give feedback rather than to evaluate. They are instructed to listen carefully to what the instructor wants to talk about-to follow, rather than lead. And if there is some glaring thing that the instructor is doing unconsciously, the consultant is to use tact and diplomacy when inserting it into the dialogue-usually by asking a question rather than making a statement (e.g., "I notice that when you are doing thus and such, you.... What is the effect you intend when you do that?"). Feedback from faculty who have been observed indicates that this method is effective.

\section{Process}

In order to build trust, consultants meet with the instructor prior to the class. This allows the instructor the opportunity to meet the person entering his or her classroom and for both to discuss teaching goals and issues. At all times, the discussion is positive and supportive, and if the teacher indicates dissatisfaction with the mandatory process, the consultant expresses empathy in a collegial manner.

After the classroom observation or S.G.I.D., the consultant and faculty member meet once more to debrief. This meeting is crucial to the consultation's success. In order to create a relaxed and open environment, the consultant must be empathetic and collaborative in his or her manner. Consequently, the faculty member will be more open to suggestions and more willing to implement them. Consultants are encouraged to offer follow-up support should the instructor wish to try some new teaching techniques. However, any further collaboration must be voluntary on the instructor's part.

\section{Follow-up}

After each consultation, a feedback form is sent to the participating faculty member. This assures quality control over the consultants' work, as well as providing feedback for subsequent consultations. Frequently, instructors ask for further information on a particular pedagogy, which al- 
lows for and encourages follow-up discussions. In the few instances where consultations were unsatisfactory, the director contacted the professor to determine the cause. In those cases, the dissatisfaction related to the "mandatory" nature of the process. Faculty members consistently report that the process itself has been a positive and useful learning experience (see Appendix 8.2 for typical qualitative faculty feedback about the process).

Ongoing consultant training. The consulting cohort meets at least once a semester to review their requirements and discuss their experiences working with Stern faculty. They often talk about specific consultations and the kinds of issues they are dealing with during the process of the STEP program. To honor the confidentiality of the clients, faculty names are never revealed.

These meetings serve as a continuing development process for the consultants as they discuss their experiences. They obtain ideas and advice from each other and in learning about others' experiences, they can be prepared for the unanticipated. In every case, the consultants report that this process has helped them learn about their own teaching. In addition, EQUAL supplies the faculty consultants with up-to-date reading materials related to the consultation process (see Appendix 8.4 for a current list of readings).

\section{Outcomes and Conclusion}

At the end of the two-year pilot period (1996-1998) Stern faculty evaluated the program. They unanimously voted to make STEP a permanent part of Stern's faculty development efforts.

Based on qualitative feedback from faculty, analysis of student evaluations, and discussions with faculty participants, Stern's administration deemed the project a success. They concluded:

Summarily, the administration and the faculty are extremely pleased with the program. The Stern Teaching Effectiveness Program continues to fulfill its initial mission by placing significant emphasis on program delivery and the highest quality education. We also are delighted to report that STEP's success is also renowned outside the Stern School of Business. In fact, it is fast becoming a model for the rest of the University, and for other schools. In our recent AACSB (American Assembly of Collegiate Schools of Business) accreditation review, the program was 
praised as an innovative and distinctive feature, and should, in the words of the AACSB consultants, be replicated nationwide.

The Stern School of Business is committed to this endeavor and understands the effect on the overall curriculum as well as the importance of good communication and platform skills to instructional effectiveness, and its subsequent and lasting impact on learning. STEP will remain an integral part of the Stern School's ongoing process of skill development and enhancement. (Stern School of Business, 1999)

As EQUAL concluded the second two-year cycle of STEP, there has been a marked increase in voluntary follow-up requests for consultations in addition to the one-time required biannual "checkup." Faculty members have had the experience of being observed in a nonthreatening way, are more trusting of the consultants, and are contacting them independently as they feel the need-signs that they are more invested in their teaching. In addition, Stern faculty are talking more about teaching in formal and informal settings. In Hutchings's (2000) terms, they have begun to develop a culture of teaching.

Unexpected benefits of this program have been

- increased alumni contributions as they learned about Stern's efforts toward improving teaching effectiveness

- other schools, departments, and programs throughout the university are now encouraged by Stern's success to experiment with structured programs that suit their individual cultures

- increased revenues to EQUAL allowed for the hiring of a full-time faculty development consultant, which enhanced its credibility and visibility, and made faculty development a more respected and supported program by the central administration

The STEP program is successful for several interrelated reasons.

- It was designed by a faculty committee and agreed to by the facultyat-large

- The school turned to a credible and respected faculty development program to administer it

- EQUAL's director made the effort to understand the Stern culture 
and trained the consulting cohort accordingly, with quality control and continuous reinforcement

- Confidentiality is guaranteed

Looking toward the future, a more systematic investigation needs to be designed to evaluate student learning outcomes and teaching improvement. However, client satisfaction with the mandatory process is a necessary first step.

\section{ACKNOWLEDGMENTS}

Special thanks to Stephanie Nickerson and Patrick McCreery for their assistance in preparing this essay.

\section{REFERENCES}

Diamond, N. (1988). S.G.I.D. (Small group instructional diagnosis): Tapping student perceptions of teaching. In E. C. Wadsworth (Ed.), $A$ bandbook for new practitioners (pp. 89-93). Stillwater, OK: New Forums Press.

Hutchings, P. (2000). Promoting a culture of teaching and learning. In D. DeZure (Ed.), Learming from Change: Landmarks in teaching and learning in bigher education from Change Magazine 1969-1999 (pp. 1-4). Sterling, VA: Stylus.

Morrison, D. (1997). Overview of instructional consultation in North America. In K. T. Brinko \& R. T. Menges (Eds.), Practically speaking: A sourcebook for instructional consultants in higher education (pp. 121-130). Stillwater, OK: New Forums Press.

Piccinin, S. (1999). How individual consultation affects teaching. In C. Knapper \& S. Piccinin (Eds.), Using consultants to improve teaching (pp. 71-83). New Directions for Teaching and Learning, No. 79. San Francisco, CA: Jossey-Bass.

Sorcinelli, M. D. (1997). The teaching improvement process. In K. T. Brinko \& R. T. Menges (Eds.), Practically speaking: A sourcebook for instructional consultants in bigher education (pp. 157-158). Stillwater, OK: New Forums Press.

Stern School of Business. (1996). Stern teaching effectiveness program (STEP). Unpublished report, New York University, Stern School Teaching Effectiveness Committee.

Stern School of Business. (1999). Stern teaching effectiveness program activities report: Academic year 1998-99. Unpublished report, New York University. 
Wilkerson, L. (1988). Classroom observation: The observer as collaborator. In E. C. Wadsworth (Ed.), A bandbook for new practitioners (pp. 95-98). Stillwater, OK: New Forums Press.

\section{Contact:}

Mona Kreaden

3 East 69th Street

New York, NY 10021

(212) $737-1752$

(212) 794-3084 (Fax)

Email: mona.kreaden@nyu.edu

Web: www.nyu.edu/projects/teaching/resources

Mona Kreaden was founding Director of EQUAL (an NYU initiative to Enhance the Quality of Undergraduate Academic Life), New York University's campus-wide faculty development initiative, which has been transformed into the Center for Teaching Excellence. Her expertise is in program development and change management. She is currently doing international consulting on how to get started in faculty development. 


\section{Appendix 8.1 \\ Stern Teaching Effectiveness Program (STEP)}

Prepared by the Stern School Teaching Effectiveness Committee

Bruce Buchanan, Eric Greenleaf, Richard Levich (Secretary),

Christine Kelly, William Silber (Chair), Richard Sylla;

Thomas Pugel, Frederick Choi (ex-officio)

Adopted by the Stern School Faculty, May 1996

\section{Background}

The creation of a Teaching Effectiveness Committee was proposed by the Faculty Council and ratified in the Fall 1995 faculty meeting. The committee was charged with the responsibility of "designing a formal teaching effectiveness program for the Stern School . . . including a training program to introduce new faculty to teaching at $S$ tern, to be put in place by the beginning of the 1996-97 academic year." We were not charged with and we did not address the evaluation of teaching performance. The Teaching Effectiveness Committee met throughout the Fall 1995 semester and presents this report for consideration by the faculty.

This report reflects the discussion at an open meeting of the faculty on March 27, and additional feedback from faculty colleagues.

\section{Introduction}

Anecdotal evidence suggests that teaching at Stern is quite good. Our goal is to see that teaching at Stern becomes even better. To do this, we want to raise the level of consciousness about teaching, and make teaching an integral feature of Stern's culture. To some degree, this consciousness-raising has already begun. In hiring, promotion and tenure decisions, increasing emphasis is being placed on teaching effectiveness. Teaching statements and teaching materials are part of each faculty member's dossier. We hope to make discussions about teaching part of the culture at Stern, much as discussions about research are already a part of that culture.

The main body of our proposal focuses on diagnostics designed to help faculty identify how to improve teaching effectiveness. Diagnostics should encompass both the delivery and substance dimensions of teaching. The committee feels that the proposal should treat all faculty equally-whether young or old, tenured or untenured, tenure-track or clinical, proficient at teaching or not. However, we also feel that it is rea- 
sonable to place separate requirements on first-year faculty to help them adapt to the Stern teaching culture.

\section{Pilot Program}

The committee recommends that we pilot the new program (Stern Teaching Effectiveness Program, or STEP) for two years. The first-year faculty will participate in both pilot years. Other faculty will participate in either year one or two. During the second year of the pilot program, the committee will evaluate the program and make a recommendation to the full faculty for adoption. If STEP is adopted, the committee will address issues of how adjunct faculty should be treated.

\section{Diagnostics}

The committee recommends that all faculty members participate in the process to enhance teaching effectiveness. The process we propose calls for each faculty member to take a more in-depth look at his or her teaching effectiveness. The committee thinks that there are many ways to obtain feedback on teaching effectiveness, and that a faculty member should be allowed to choose from a set of alternatives.

\section{Diagnostic Alternatives}

After considering a number of alternatives, the committee proposes four specific diagnostic processes:

(i) Videotaping. A classroom session is videotaped and evaluated by a trained consultant. The faculty member and consultant review the tape. The consultant offers suggestions for improving teaching effectiveness.

(ii) Audit by Communications Expert. A classroom session is audited and evaluated by a trained consultant. The faculty member and the consultant review the consultant's evaluation. The consultant offers suggestions for improving teaching effectiveness.

(iii) Small Group Instructional Diagnostic. A classroom session is audited by a trained consultant. Toward the end of the class, the instructor leaves the room and the consultant takes over. Students are divided into groups of 4-8 and given about 3 minutes to discuss each of three questions: What do you like about the class, what needs improvement in the class, and what specific suggestions do you have for improving the class? The class reassembles, and the consultant invites 
each group to report back their answers to the three questions. Discussion develops during the reporting process. The consultant writes a report and meets with the faculty member to review the suggestions. [This aspect of the process differentiates it from a "focus group" run by a trained facilitator who might not be familiar with teaching.] The faculty member completes the process by discussing the results with the class and deciding what steps (if any) will be taken.

(iv) Peer Review/Faculty Pairing. A classroom session is attended by a fellow faculty member, who then provides feedback on possible ways to improve teaching effectiveness.

\section{More About the Diagnostic Process}

(i) Confidentiality. The committee thinks that the results of the annual diagnostic choice must be held confidential. The videotape and all copies of reports must be turned over to the faculty member at the end of the process. The purpose of the diagnostic process is to improve teaching effectiveness, not to provide an alternative measurement and/or reporting method on attained teaching performance.

(ii) Professional and Impartial Evaluation. The committee thinks that (except when the Peer Review/Faculty Pairing option is chosen) the diagnostic evaluation must be performed by a professionally trained consultant.

(iii) The Small Group Instructional Diagnostic. The committee hopes that faculty would find it in their interest to try this diagnostic procedure, which is already being offered at NYU through the EQUAL commission. A number of Stern faculty have recently tried this technique and have been happy with the results. A one-page description of the program is attached for your information.

(iv) Peer Review/Faculty Pairing. The faculty member undergoing review should select a faculty reviewer in consultation with his or her department Chair.

\section{First-Year Faculty}

The committee believes that first-year faculty should be required to make additional preparations to enhance their teaching effectiveness, and in- 
crease their familiarity with the teaching culture at Stern. We propose three components for first-year faculty:

(i) Orientation: Workshop. First-year faculty should be required to attend the orientation workshop on teaching organized by the Management Communication area.

(ii) First Semester: Audit Stern MBA Classes. Most first-year faculty are granted a reduced teaching load of two rather than three Stern classes. The committee proposes that during their first semester at Stern, first-year faculty be required to audit (attend) classes of experienced faculty. In many cases, it would be desirable to audit classes of the course that the new faculty member will teach in the Spring semester, but this need not be a requirement. The details of the audit could be worked out with the department chairperson. The faculty member would submit a report on these activities as part of the annual Faculty Activities Report.

(iii) Second Semester: Diagnostic Alternatives. In the second (Spring) semester, the first-year faculty member would select from among the four alternatives provided to other Stern faculty (videotape, expert audit, small group diagnostic, or peer review).

\section{Faculty Responsibilities}

To insure that faculty participate in the diagnostic process, we recommend that each faculty member report which diagnostic procedure he or she elected on the annual Faculty Activities Report.

\section{Oversight of the STEP Program}

Based on feedback from the open meeting, we recommend that STEP be implemented using a decentralized approach. The Dean's office will provide the resources necessary for arranging the alternative STEP diagnostics. Department Chairs will inform faculty about the scheduling and availability of alternative STEP diagnostics, and work informally to smooth the demand for STEP diagnostics throughout the pilot program. The Stern Teaching Effectiveness Committee will retain an oversight role to monitor the overall design and implementation of the STEP initiative. 


\section{Culture Building}

In addition to the STEP proposal, the committee discussed other initiatives that might be implemented to enhance the culture of teaching at Stern.

(i) Multiple Section Courses: We suggest that in all multiple section courses (such as the core, but perhaps also in elective courses), faculty meet for discussions of teaching effectiveness and delivery as well as for content. Core-course faculty already meet regularly and could reallocate some discussion time toward teaching effectiveness issues. Faculty in multiple sections of non-core courses should develop a mechanism for meeting on these issues.

(ii) Teaching Retreat: The Dean's Office might arrange an ongoing series or a periodic off-campus program, where sessions on teaching practice would be given to and by faculty. Specific activities could include the following: (a) Faculty member gives a class, or a case, to colleagues which is followed by a discussion of the teaching technique and its success; (b) Faculty meet in groups to review and discuss class tapes; (c) Core course faculty meet to discuss interactions among the core courses; (d) Faculty with particularly innovative teaching ideas, such as multi-media or computer-assisted teaching, present them to other faculty.

(iii) Teaching Resources Center: We suggest that the Dean's Office establish a library of teaching materials, such as classroom videos, cases, examinations, and so forth to help faculty improve teaching skills on their own.

\section{Conclusions}

The objective of the STEP program is not necessarily to make everyone a teaching "superstar." Rather, the program is designed to make an already highly effective teaching faculty even better. We expect that everyone's teaching effectiveness will be enhanced by the diagnostic procedures proposed here, as well as by the increased attention paid to the teaching process. 


\section{APPENDIX 8.2 \\ Application: Stern STEP Program \\ BACKGROUND INFORMATION}

\section{Contact Information}

Name:

(Please circle) Full, Associate, Assistant, Adjunct, Clinical, TA, Ph.D. Student, Post Doc.

School: Dept:

Phone:

Office Address: Fax:

Mail Code:

Course Name \& \# :

Grad: Undergrad:

Class Location: Day \& Time:

\# of Students:

Years at NYU? Email:

Service Requested:

Observation Video w/ observation (2) S.G.I.D.

Preferred Dates: (1)

(Please choose dates at least 10 business days after application submission)

Please answer the following questions to help us select the best consultant for you. If necessary, use a separate page. Upon completion, mail or fax two copies of your syllabus, your answers and this form to the above address. If your syllabus is on the Web, please write the URL so we can access it easily.

1. Describe briefly the content and structure of your course.

2. What are your course objectives?

3. What do you see as your strengths in teaching this course?

4. Do you have any specific teaching issues that you are interested in exploring?

5. What do you hope to get out of this process? 
6. Why are you requesting this particular type of service?

7. Indicate your preference for faculty consultant:

From Stern Not from Stern

\title{
How to Take Advantage of EQUAL's Faculty Consultation Services
}

\author{
EQUAL consultants do not judge your performance \\ but rather observe and offer feedback. \\ All consultations are strictly CONFIDENTIAL.
}

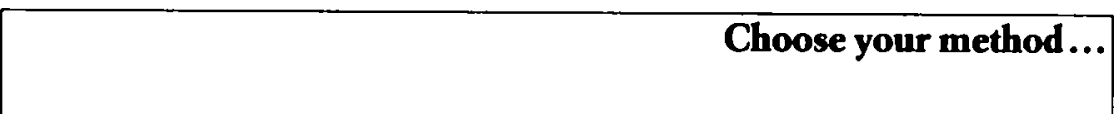

EQUAL provides three types of in-class service: Observation, Observation with Video and Small Group Instructional Diagnosis (S.G.I.D.).

Observation: At a mutually convenient time, an EQUAL consultant will sit in on your class and then review his or her confidential observation notes with you.

Video with Observation: Videotaping gives you information about your teaching style, and very often the picture is worth a thousand words. The effectiveness of an observation is often enhanced by simultaneous video taping. At the end of class, you are given the video to view privately prior to your consultation. You also receive a checklist to help focus the discussion. At a mutually convenient time, an EQUAL consultant will review his or her confidential observation notes and video with you.

Small Group Instructional Diagnosis (S.G.I.D.): S.G.I.D. is an assessment technique using small student group discussion to strengthen a course, increase student/teacher communication and improve teaching performance. An EQUAL consultant observes your class and after you leave the room, divides students into small groups to address these questions: What do you like about this class? What do you think needs improvement? What suggestions would you make? Results are tabulated and presented to you during a confidential one-on-one consultation. This method identifies problem areas and generates alternative solutions. Secondary benefits can include increased student interest, acceptance of course methodology and improved end of semester evaluations. The S.G.I.D. is done at mid-semester which allows time for course changes, 
if necessary. The actual process takes the last 20 to 30 minutes of class time (for 50+ students, 40-45 minutes).

Return the application.

A consultant will meet with you in advance to learn about your goals, objectives, strengths and concerns. This helps him or her to better observe your class, analyze your video or work with your students. When applying, make sure you answer all the questions and attach two copies of your syllabus to help facilitate this pre-observation discussion.

Inform your students...

Our office will take care of the logistics and send you a written confirmation. Run your class as usual but inform your students that a videographer and/or consultant will be present.

Meet with your consultant...

After the observation and at a convenient time, your consultant will meet with you to review the observation notes, video or S.G.I.D. results. EQUAL consultants do not judge your performance but rather observe and offer feedback. All consultations are strictly CONFIDENTIAL.

Tell us how we're doing...

After completing your consultation, you will be mailed an evaluative feedback form by our office. Your suggestions and advice are important to us! 


\section{APpendix 8.3}

\section{Typical Faculty Feedback About the Consulting Process}

\section{What Did You Like About This Process?}

3/99 An Information Systems Professor: "I just want to thank you for your truly outstanding mid-semester evaluation of my new class. I just went through the notes again and I am still impressed by how many insights you manage to convey. I have no doubt that what you have taught me will be very useful far beyond this course. Thank you."

3/99 A Marketing Professor. "Specific things that I liked were that [the consultant] talked to me about my objectives before class, but left me some time to get things together beforehand. She was unobtrusive in class and able to debrief promptly. She did a great job of tracking and diagramming what happened in class-an interesting perspective for me. She had some theory to offer that gave me useful labels for some things that I do and insight into relationships between teaching and learning (but didn't do this in a heavy-handed way). She kept my objectives in mind and responded to them thoughtfully. Finally, she didn't feel a need to spend more time discussing things than I found useful."

3/99 An Award Winning Finance Professor: "Unobtrusive observation with excellent suggestions and comments. [The consultant] observed details about the classroom that I was never aware of. Excellent comments."

11/98 A Management Professor: "It was a great opportunity to have someone who has terrific pedagogical sensibilities give objective feedback on the design and delivery of a course in a subject that was new to the observer. And it was non-threatening!"

\section{What Suggestions Would You Make?}

4/98 An International Business Professor: "A series of sessions."

4/98 An Accounting Professor: "Perhaps for those of us who want it, a follow-up visit (by the same consultant) would be helpful, to see if some of his/her recommendations were effectively adopted."

12/97 A Management Professor: "Multiple observations would provide more representative data."

10/97 A Statistics Professor: "The course in teaching effectiveness probably should be extended beyond one class, i.e., three or four meetings. 


\section{Was the Consultant Responsive to Your Needs?}

3/99 A Marketing Professor: "I found [the consultant] to be a total professional with an excellent understanding of feedback, classroom skill requirements, and the ability to explain her evaluation. Make sure that all consultants are as qualified, professional, sensitive and have equal communications skills."

11/98 A Management Professor: '[The consultant] displayed a high level of sensitivity and insight into the myriad of ideas, experiences and emotions that go into the development and delivery of a course. She helped me become aware of the strengths of my course design and reflected while creating a constructive context for improvement where appropriate."

2/98 An Economics Professor: "Everything was thoroughly professional! [The consultant] was unobtrusive; she did an excellent job. We met before class. I explained the 'procedure' in my approach to teaching. She blended in perfectly. Our meeting the next morning (post-observation discussion) went very well. I was amazed by how expertly she analyzed what I had tried to do. Thank you." 


\section{APpendix 8.4 \\ ReAding List}

Currently (January 2001), EQUAL Faculty Development Consultants have been reading excerpts, chapters, and articles from the following sources.

- Border, L., \& Chism, N. V. N. (Eds.). (1992). Teaching for diversity. New Directions for Teaching and Learning, No. 49. San Francisco, CA: Jossey-Bass.

- Brinko, K. T., \& Menges, R. J. (Eds.). (1997). Practically speaking: A sourcebook for instructional consultants in higher education. Stillwater, OK: New Forums Press.

- Christensen, C. R., Garvin, D. A., \& Sweet, A. (1991). Education for judgment: The artistry of discussion leadership. Boston, MA: Harvard Business School Press.

- Marincovich, M., Prostko, J., \& Stout, F. (Eds.). (1998). The professional development of graduate teaching assistants. Bolton, MA: Anker.

- Pratt, D. D., \& Associates. (1998). Five perspectives on teaching in adult and bigher education. Malabar, FL: Krieger.

- Sorcinelli, M. D. (1986). Guidelines for classroom observation. Evaluation of teaching handbook. Bloomington, IN: Dean of the Faculties Office. Reprinted in Weimer, M. (1991). Improving college teaching. San Francisco, CA: Jossey-Bass. 